\title{
LA DOCTRINA DEL MARGEN \\ DE APRECIACIÓN NACIONAL \\ SU RECEPCIÓN EN EL SISTEMA \\ EUROPEO DE DERECHOS HUMANOS, \\ EN EL SISTEMA INTERAMERICANO \\ DE DERECHOS HUMANOS Y EN ARGENTINA.
}

\author{
MARCELO ALBERTO LÓPEZ ALFONSÍN ${ }^{1}$ y \\ MARÍA SOL BUCETTO ${ }^{2}$
}

\section{RESUMEN}

El margen de apreciación nacional es una pauta hermenéutica nacida en el sistema europeo que profiere a los Estados un margen de deferencia para que interpreten las normas convencionales, atendiendo al contacto más directo que las autoridades nacionales tienen con la sociedad civil. Los alcances de esta teoría han trascendido las fronteras hasta ser receptados por el sistema interamericano y el Estado argentino, en particular. Las diferencias contextuales permiten realizar una comparación que muestran al sistema interamericano en una posición más retrasada respecto a su par europeo. En el caso argentino, se ha reconocido la teoría pero no ha alcanzado un fructífero desarrollo.

\section{PALABRAS CLAVE:}

Margen de apreciación nacional, jurisprudencia del sistema europeo de derechos humanos, jurisprudencia del sistema interamericano de derechos humanos, jurisprudencia argentina.

1 Docente Universidad de Buenos Aires, Argentina

2 Docente Universidad de Buenos Aires, Argentina 


\section{ABSTRACT}

The national margin of appreciation is a hermeneutic rule born in the European system, which gives States a margin of deference to interpret conventional standards, taking the most direct contact national authorities have with civil society. The scope of this theory has transcended its primitive borders to be adopted by the inter-American system and Argentina, in particular. Contextual differences allow a comparison that shows the inter-American system in a rear most position relative to its European counterpart. In Argentina, this theory has been recognized, but has not reached a successful development.

\section{KEY WORDS:}

National margin of appreciation, jurisprudence of the European system of human rights, jurisprudence of the inter-American system of human rights, jurisprudence of Argentina. 


\section{INTRODUCCIÓN}

En el presente trabajo pretendemos abordar la cuestión de la doctrina del margen de apreciación nacional, desde su creación jurisprudencial por parte de los organismos del sistema europeo de derechos humanos, hasta su recepción en el continente americano.

Para ello, comenzaremos por realizar una conceptualización de la teoría, a fin de poder identificar sus elementos constitutivos y alcance.

Más adelante, estudiaremos la trascendencia que ha tenido esta doctrina y su reflejo en el sistema interamericano, con el objeto de poder realizar una comparación aproximada entre ambos sistemas regionales.

Por último, realizaremos un breve recorrido por las decisiones jurisprudenciales argentinas en las que se ha recurrido a la doctrina del margen de apreciación nacional, procurando una evaluación de la situación que defina si es posible una mayor apertura hacia los preceptos del sistema europeo en nuestro país.

\section{LA DOCTRINA DEL MARGEN DE APRECIACIÓN. CONCEPTUALIZACIÓN CONFORME EL SISTEMA EUROPEO DE DERECHOS HUMANOS}

La doctrina del margen de apreciación nacional encuentra su origen como criterio hermenéutico instaurado por los organismos del sistema europeo, a fin de interpretar y aplicar el Convenio Europeo de Derechos Humanos. Al ser un concepto jurídico de construcción pretoriana, su alcance es aún indeterminado, por lo 
cual resulta inevitable recurrir a los precedentes jurisprudenciales para poder lograr una cabal comprensión de su significado.

En orden de procurar una primera aproximación, tomaremos en cuenta que esta doctrina puede ser entendida como un espacio de discrecionalidad con la que cuentan los Estados Partes, para fijar el contenido y alcance de los derechos del Convenio Europeo, tomando en consideración determinadas circunstancias jurídicas, sociales y culturales (GONZÁLEZ VEGA, 2004, "Interpretación, Derecho Internacional y Convenio Europeo de Derechos Humanos: a propósito de la interpretación evolutiva en materia de autodeterminación sexual" 178). Su existencia se encuentra justificada por la ausencia de un consenso entre los diferentes Estados parte dentro de los tratados, lo que hace que los tribunales regionales se encuentren impedidos para la posible construcción de una regla de interpretación unificada (BARbosa Delgado, Francisco R., 2012, El margen nacional de apreciación en el derecho internacional de los derechos humanos: entre el estado de derecho y la sociedad democrática 53).

El fundamento del margen de apreciación no se encuentra en el texto del Convenio Europeo, se trata más bien, de un instrumento interpretativo que parte de la idea de que un derecho no puede juzgarse en abstracto, omitiendo los marcos culturales y económicos que lo circundan, por el contrario existen condicionamientos materiales y sociales cuyo desconocimiento quitaría realidad o vigencia a un régimen de derechos humanos (SAGÜÉS, Néstor, 2003, "Las relaciones entre los Tribunales Internacionales y los Tribunales Nacionales en materia de derechos humanos. Experiencias en Latinoamérica” 219). 
Este poder de deferencia del tribunal regional hacia los estados frente a circunstancias en las cuales no existe ningún tipo de consenso interestatal, refuerza el carácter subsidiario de la jurisdicción internacional, que sólo interviene sobre eventuales violaciones de derechos humanos, tras el agotamiento de los recursos internos y bajo el presupuesto de que el Estado se encuentra en mejor posición que los organismos internacionales para resolver sobre determinados aspectos del caso.

Así ha entendido el Tribunal Europeo de Derechos Humanos, que la CEDH tenía un carácter subsidiario frente a la acción del Estado producto de su voluntad, cuando recordó que existen aspectos de la vida social en los cuales "[...] las autoridades nacionales son libres de escoger las medidas que estimen apropiadas dentro de los aspectos regidos por la Convención [...]" (BArbosa Delgado, 57, citando TEDH, 1968, Caso relativo a ciertos aspectos de la legislación linguística de la enseñanza en Bélgica: 10).

Esta doctrina surgió cuando los órganos del sistema europeo se vieron obligados a interpretar el artículo 15 de CEDH. El mismo establece la posibilidad de suspender ciertos derechos ante una situación de peligro público. En ese contexto, el margen estaba ligado a una lógica de discrecionalidad del Estado a la hora de valorar las exigencias de una situación de emergencia, que limitaba la intensidad de la supervisión de la Comisión cuando valorase las medidas adoptadas (GARcíA RocA, 2007, "La muy discrecional doctrina del margen de apreciación nacional según el tribunal europeo de derechos humanos: soberanía e integración” 122). 
Los primeros antecedentes de este concepto se remontan a la actuación de la Comisión Europea de Derechos Humanos en los asuntos Grecia c. Reino Unido ${ }^{3}$, Lawless c. Irlanda ${ }^{4}$, y Dinamarca, Noruega, Suecia y Países Bajos c. Grecia ${ }^{5}$.

El Tribunal Europeo fue más reticente en la utilización de la doctrina, ya que no fue sino hasta, en el caso De Wilde, Ooms y Versyp c. Bélgica, de 18 de junio de 1971, en el que utilizó por primera vez la expresión "margen nacional de apreciación", en el cual indicó que la medida de detención contra un grupo de vagabundos no había vulnerado el artículo 8.2 de la CEDH, toda vez que el Estado pudo tener razones valederas y necesarias para defender el orden y prevenir las infracciones penales contra la moral, la salud y la reputación de los otros (BARbosa Delgado, 2012 52, citando TEDH, 1972, De Wilde, OOms et Versyp contra Bélgica $)^{6}$.

Como mencionáramos precedentemente, los primeros asuntos en los que la Comisión hizo uso de esta doctrina planteaban supuestos recubiertos de cierta excepcionalidad, ya que se enjuiciaban medidas de derogación de los derechos reconocidos

$3 \mathrm{CEDH}$, Grecia c. Reino Unido, dictamen del 26 de septiembre de 1958.

4 CEDH, Lawless c. Irlanda, dictamen del 19 de diciembre de 1959. Este caso fue luego resuelto por el TEDH, en 1961, retomando los conceptos vertidos por la Comisión.

5 CEDH, Dinamarca, Noruega, Suecia y Países Bajos c. Grecia, dictamen del 5 de noviembre de 1969.

6 Previo a esto, el TEDH resolvió otros casos utilizando la doctrina del margen de apreciación, pero sólo haciendo referencia a lo dicho previamente por la Comisión. Sirva de ejemplo para ello el caso Lawless c. Irlanda mencionado anteriormente. 
en el Convenio, adoptadas por los Estados en virtud de lo previsto en el artículo 15 CEDH. Sin embargo, la doctrina del margen sería incorporada posteriormente a asuntos en los que se debatían eventuales vulneraciones de otros preceptos del CEDH, como por ejemplo, el derecho a la educación, en el caso Lingüístico Belga7, o la libertad de expresión, en el asunto Handyside ${ }^{8}$ (DíAz CREGO, 2011, "Margen de apreciación” 2).

El TEDH mantuvo esta línea de pensamiento en el caso Irlanda contra el Reino Unido, en el cual el señaló:

[...] Incumbe a cada Estado contratante, responsable de la vida de la nación, determinar si un peligro público lo amenaza y si esto ocurre evaluar los medios que tiene para disiparlo... las autoridades nacionales se encuentran en principio, en mejor lugar, que el juez internacional para pronunciarse sobre la presencia de ese peligro, así como sobre la naturaleza y el alcance de las suspensiones para conjurarlo. El artículo 15 permite un amplio margen de apreciación [...] (Barbosa Delgado, 58, citando TEDH, 1976, Irlanda vs. Reino Unido)

Ahora bien, existe un aspecto fundamental que no debe pasar inadvertido: el hecho de que el ejercicio del margen de apreciación nacional encuentra límites intrínsecos y extrínsecos. En primer término, las autoridades nacionales deben honrar las

7 TEDH, Lingüístico Belga, sentencia del 24 de junio de 1965.

8 TEDH, Handyside v. United Kingdom, sentencia del 7 de diciembre de 1976. 
obligaciones asumidas al momento de ratificar los tratados de derechos humanos. En el caso europeo, la CEDH no establece de forma expresa las obligaciones a las que someten los Estados cuando la ratifican. Sin embargo, de la lectura del artículo $1^{\circ}$ se desprende que los Estados deben reconocer a toda persona, independiente de su jurisdicción, los derechos y libertades consagrados en la Convención (BARbosa Delgado, 2011, "Los límites a la doctrina del margen nacional de apreciación en el Tribunal Europeo y la Corte Interamericana de Derechos Humanos: intervención judicial en torno a ciertos derechos de las minorías étnicas y culturales").

Asimismo, aquel margen de apreciación otorgado a los Estados nunca podrá ser absoluto y deberá someterse al control de proporcionalidad por parte de los organismos internacionales de protección de derechos humanos. En este sentido, los Estados podrán establecer restricciones a los derechos mientras sean conformes con los estándares de la necesidad de la medida adoptada y la idoneidad de los instrumentos utilizados para ponerla en práctica9 .

El propio margen de apreciación nacional es un ingrediente más de ese juicio de proporcionalidad. Un límite estructural a su aplicación que permite no entrar a revisar en ciertos casos la interferencia en el derecho si el fin de la restricción es legítimo, y la medida y la regulación son necesarias a ojos de las autoridades

9 El TEDH sostuvo la idea del control europeo en base a los estándares de proporcionalidad y justificación en los asuntos Eweida v. Reino Unido y Animal Defenders International v. United Kingdom, entre otros. (Véase TEDH, Eweida v. Reino Unido, sentencia del 15 de enero de 2013 y TEDH, Animal Defenders International v. United Kingdom, sentencia del 22 de abril de 2013) 
nacionales y todo ello no resulta irrazonable a la Corte (GARCíA RocA )

La idea básica es, pues, que los Estados partes tienen un cierto margen de discrecionalidad en la aplicación y el cumplimiento de las obligaciones impuestas por el Convenio y en la ponderación de intereses complejos. No obstante, si en el uso de esa discrecionalidad que el margen permite, el Estado se sobrepasa y se produce un exceso, un ultra vires, aunque parezca en sí mismo legítimo, la lógica del respeto al principio de proporcionalidad aboca a una supervisión europea (GARCíA RocA, 122).

En el mismo orden de ideas, el TEDH sostuvo que, además de los parámetros bien definidos de la proporcionalidad, el margen de apreciación también dependerá de varias circunstancias inherentes a los derechos protegidos, que pueden oscilar en función de las particularidades que cada caso contempla (PASCUAL VIVES, 2013, "El margen de apreciación nacional en los tribunales regionales de derechos humanos: una aproximación consensualista” 237, citando TEDH, 1984, Rasmussen v. Denmark, 40).

\section{LA DOCTRINA DEL MARGEN DE APRECIACIÓN NACIONAL EN EL SISTEMA INTERAMERICANO DE DERECHOS HUMANOS}

El sistema interamericano de protección de los derechos humanos no ha quedado exento del progresismo propuesto por los organismos europeos respecto de la doctrina del margen de apreciación. Si bien su aplicación ha sido menos profusa, es posible mencionar algunos casos en los que tanto la Comisión como la Corte Interamericana han recurrido a esta teoría. 
Los instrumentos de este sistema regional, al igual que el europeo, no receptan expresamente la doctrina en cuestión. No obstante, la CADH fue más precisa en cuanto a la enunciación de las obligaciones de respetar los derechos y libertades reconocidos en ella y garantizar su libre y pleno ejercicio a toda persona que esté sujeta a su jurisdicción, sin discriminación alguna; junto a la previsión de tomar las medidas necesarias para adaptar el ordenamiento interno a las normas de la Convención (arts. 1 y 2 respectivamente) Esta última disposición permite inferir que es el Estado el encargado de la interpretación y aplicación del articulado de la Convención Americana dentro de su jurisdicción.

Como lo explica Faúndez Ledesma:

[...] La idea de que el Estado pueda ejercer un margen de apreciación en la aplicación de la Convención no se encuentra expresamente reconocida por la Convención Americana, y tiene que ser vista, si no con recelo, por lo menos con mucha precaución; sin embargo es evidente que esta doctrina también tiene aplicación en el sistema interamericano y que es inherente a las expresiones utilizadas por algunas de sus disposiciones [de la $\mathrm{CADH}]$ [...] (2004, El sistema interamericano de protección de los derechos humanos. Aspectos institucionales y procesales 57) ${ }^{10}$

10 En contraposición a esta postura, Antonio CANÇADO TRINDADE, ha sostenido que "[...] [a]fortunadamente tal doctrina no ha encontrado un desarrollo paralelo explícito bajo la Convención Americana sobre Derechos Humanos [...]" (Véase CANÇADO TRINDADE, Antonio, El derecho internacional de los derechos humanos en el siglo XXI, 2a. ed., Santiago: Editorial Jurídica de Chile, 2006, 389) 
En la Comisión Interamericana se han destacado algunos informes de admisibilidad, como son los casos Álvarez Giraldo ${ }^{11}$, Sánchez Villalobos $^{12}$ y Cháves Cambronero ${ }^{13}$. En los tres casos, la CIDH restringió el margen nacional de apreciación de los Estados y protegió el derecho de ciertas minorías con el argumento que no puede extenderse concepciones sociales de restricción y/o violación de derechos humanos en el continente americano (Barbosa Delgado, 58).

Del mismo modo, en el caso Efraín Ríos Montt c. Guatemala, la CIDH aplicó el principio reconociendo la variabilidad de las reglas de elegibilidad para los cargos de elección popular. Sobre el punto ha dicho:

[...] [E]l contexto del derecho constitucional guatemalteco e internacional en que se ubica esta condición de inelegibilidad es la dimensión apropiada para el análisis de la aplicabilidad de la Convención en general, y de sus artículos 23 y 32 al caso sub-judice, y de la cual puede surgir el margen de apreciación permitido por el derecho internacional [...] (CIDH, 1993, Caso José Efraín Montt vs. Guatemala, 24)

11 CIDH, Informe Núm. 71/99, caso núm. 11.656, Marta Lucía Álvarez Giraldo vs. Colombia, 4 de mayo de 1999.

12 CIDH, Informe Núm. 25/04, petición núm. 12.361 Admisibilidad, Ana Victoria Sánchez Villalobos y otros vs. Costa Rica, 11 de marzo de 2004.

13 CIDH, Informe Núm. 50/05, petición núm. 369-04 Admisibilidad, Jorge Luis Cháves Cambronero vs. Costa Rica, 12 de octubre de 2005. 
A mayor abundamiento, la CIDH remarcó que esta doctrina es de aplicación restrictiva y excepcional, dado que encuentra límites precisos en cuanto a un contexto temporal y espacial determinado. Estas fueron sus palabras:
[...] Al respecto recuerda la Comisión que esto debe analizarse de acuerdo a las circunstancias del caso y las concepciones jurídicas prevalecientes en el período histórico. Nuevamente aquí la Comisión debe reafirmar el carácter restrictivo con que debe utilizar ese margen de apreciación, el cual debe ser siempre concebido tendiente al refuerzo del sistema y sus objetivos [...] $(\mathrm{CIDH}$, 1993, Caso José Efraín Montt vs. Guatemala, 31)

De igual manera, la CIDH, en el caso Robelo González, consideró que la definición de la nacionalidad es otra de las atribuciones retenidas por cada autoridad estatal. Ha dicho:

[...] La regulación y determinación de la nacionalidad es competencia de cada Estado soberano; a éste le corresponde regular con sus leyes la adquisición de la propia nacionalidad, como así también la nacionalidad por naturalización. En efecto, cada Estado estipula, de manera soberana, la normativa sobre adquisición, pérdida y recuperación de la nacionalidad [...] (CIDH, 2001, Caso Álvaro Robelo González vs. Nicaragua, 49)

En lo que respecta a la actuación de la Corte Interamericana, es dable afirmar que desde temprano ha receptado la doctrina del 
margen de apreciación nacional. Como primer punto, debemos mencionar la Opinión Consultiva 4/84. La Corte fue llamada a interpretar la compatibilidad de las disposiciones de la $\mathrm{CADH}$, en particular las garantías de igualdad y no discriminación, con referencia a un proyecto de reforma de la Constitución Política de Costa Rica, que estipulaba condiciones preferentes para obtener la nacionalidad costarricense por naturalización en favor de ciertos grupos de extranjeros y en detrimento del resto.

Al evaluar la situación, el Tribunal concluyó que el Estado goza de un margen de apreciación para el establecimiento de requisitos para la naturalización de extranjeros o para precisar los imperativos del bien común, al momento de realizar una distinción de trato. Sin embargo, dejó a salvo que la decisión tomada a la luz del margen de apreciación no debe ser ilegítima, conforme el principio de proporcionalidad que debe guiar el accionar estatal. Así lo ha expresado:

[...] No habrá, pues, discriminación si una distinción de tratamiento está orientada legítimamente, es decir, si no conduce a situaciones contrarias a la justicia, a la razón o a la naturaleza de las cosas [...]

[...] Si bien no puede desconocerse que las circunstancias de hecho pueden hacer más o menos difícil apreciar si se está o no en presencia de una situación como la descrita en el párrafo anterior, es también cierto que, partiendo de la base de la esencial unidad de la dignidad del ser humano, es posible apreciar circunstancias en que los imperativos del bien común puedan justificar un mayor o menor 
grado de distinciones que no se aparten de las consideraciones precedentes. Se trata de valores que adquieren dimensiones concretas a la luz de la realidad en que están llamados a materializarse y que dejan un cierto margen de apreciación para la expresión que deben asumir en cada caso [...] (Corte IDH, 1984, Opinión Consultiva OC-4/84, 57 y 58)

Para mayor claridad respecto de los límites del margen de apreciación, la Corte Interamericana prosiguió:

[...] Esa conclusión de la Corte tiene especialmente en cuenta el margen de apreciación reservado al Estado que otorga la nacionalización sobre los requisitos y conclusiones que deben llenarse para obtenerla. Pero de ningún modo podría verse en ella una aprobación a la tendencia existente en algunas partes a restringir exagerada e injustificadamente el ámbito de ejercicio de los derechos políticos de los naturalizados [...] (Corte IDH, 1984, Opinión Consultiva OC-4/84, 62)

En relación con los casos contenciosos, la idea del margen de apreciación ha tenido su mayor desarrollo en cuanto al derecho a los recursos (contemplado en el artículo 8 de la $\mathrm{CADH}$ ). $\mathrm{Al}$ respecto, vale citar el caso Herrera Ulloa c. Costa Rica, a través del cual la Corte reconoce la existencia del margen de apreciación para establecer regulaciones a los recursos disponibles en el 
orden interno, pero lo circunscribe a la imposibilidad de limitar la esencia del derecho ${ }^{14}$.

[...] Si bien los Estados tienen un margen nacional de apreciación para regular el ejercicio de ese recurso, no pueden establecer restricciones o requisitos que infrinjan la esencia misma del derecho a recurrir el fallo. Al respecto, la Corte ha establecido que "no basta con la existencia formal de los recursos sino que éstos deben ser eficaces", es decir, deben dar resultados o respuestas al fin para el cual fueron concebidos [...] (Corte IDH, 2004, Caso Herrera Ulloa Vs. Costa Rica, 161) $)^{15}$

Otro de los temas ampliamente desarrollado por la Corte Interamericana ha sido el de las restricciones al derecho a la libertad de expresión. Sobre este punto, se ha reconocido un margen de apreciación muy reducido, ya que este derecho es considerado como un pilar básico para la constitución de una sociedad democrática. A razón de ello, el test de proporcionalidad aplicado para declarar conforme a la Convención una restricción de la libertad de expresión es muy riguroso y ha sido detalladamente explicitado por la Corte.

14 En el caso Chaparro Álvarez y Lapo contra Ecuador, referido a la libertad personal, la Corte IDH también se refirió al principio de proporcionalidad y racionalidad al momento de establecer restricciones. Véase Corte IDH. Caso Chaparro Álvarez y Lapo Íñiguez Vs. Ecuador. Excepciones Preliminares, Fondo, Reparaciones y Costas. Sentencia de 21 de noviembre de 2007. Serie C No. 170, 107.

15 Véase también en Corte IDH. Caso Barreto Leiva Vs. Venezuela. Fondo, Reparaciones y Costas. Sentencia de 17 de noviembre de 2009. Serie C No. 206, 90. 
A fin de no excedernos del marco de este trabajo, sólo diremos que los Estados podrán apelar al margen de apreciación para establecer restricciones en esta materia siempre que la limitación esté prevista legalmente (expresa y taxativamente en una ley en sentido formal), sea necesaria en una sociedad democrática, esté orientada a satisfacer un interés público imperativo, no limite más de lo estrictamente necesario el alcance pleno de la libertad de expresión y no se convierta en un mecanismo de censura ${ }^{16}$.

Por último, mencionaremos el caso Castañeda Guzmán contra México, referido a los derechos políticos (contemplados en el art. 23 de la CADH) y los sistemas electorales. Al respecto, la Corte estipuló que el sistema interamericano no protege un determinado sistema electoral, ya sea de partidos o candidaturas independientes, sino que cada Estado tiene un margen nacional de apreciación para establecer los requisitos para ejercitar los derechos políticos, siempre y cuando las regulaciones y

16 Sobre este tema véase Corte IDH. La colegiación obligatoria de periodistas (Arts. 13 y 29 Convención Americana sobre Derechos Humanos). Opinión Consultiva OC-5/85 de 13 de noviembre de 1985. Serie A No. 5; Corte IDH. Caso Herrera Ulloa Vs. Costa Rica. Excepciones Preliminares, Fondo, Reparaciones y Costas. Sentencia de 2 de julio de 2004. Serie C No. 107; Corte IDH. Caso Ricardo Canese Vs. Paraguay. Fondo, Reparaciones y Costas. Sentencia de 31 de agosto de 2004. Serie C No. 111; Corte IDH. Caso Palamara Iribarne Vs. Chile. Fondo, Reparaciones y Costas. Sentencia de 22 de noviembre de 2005. Serie C No. 135; Corte IDH. Caso López Álvarez Vs. Honduras. Fondo, Reparaciones y Costas. Sentencia de 1 de febrero de 2006. Serie C No. 141; Corte IDH. Caso Kimel Vs. Argentina. Fondo, Reparaciones y Costas. Sentencia de 2 de mayo de 2008. Serie C No. 177; Corte IDH. Caso Perozo y otros Vs. Venezuela. Excepciones Preliminares, Fondo, Reparaciones y Costas. Sentencia de 28 de enero de 2009. Serie C No. 195, entre otros. 
restricciones superen el estándar de razonabilidad. En claras palabras del Tribunal:

[... El sistema interamericano tampoco impone un sistema electoral determinado ni una modalidad específica para el ejercicio de los derechos a votar y a ser votado. La Convención Americana establece lineamientos generales que determinan un contenido mínimo de los derechos políticos y permite a los Estados que dentro de los parámetros convencionales regulen esos derechos de acuerdo a sus necesidades históricas, políticas, sociales y culturales, las que pueden variar de una sociedad a otra, e incluso en una misma sociedad, en distintos momentos históricos [...] (Corte IDH, 2008, Caso Castañeda Gutman Vs. México, párr. 166)

Como se observa en estas decisiones, el tribunal expone los límites del Estado en cuanto a la protección de la libertad de expresión, libertad personal y a los derechos políticos, otorgándole un espacio para que pueda tener una visión propia -margen de apreciación - dentro de los estrictos límites fijados por la Corte. Esta posición evidencia la manera como se reconoce el margen nacional de apreciación por parte de la Corte IDH (Barbosa Delgado, 60)

Con todo, es posible apreciar ciertos paralelismos que auguran, como en otras materias, una progresiva recepción de esa técnica de adjudicación. Sin el ánimo de ser exhaustivos, pueden identificarse someramente seis áreas en las que se ha aplicado de alguna forma la doctrina en estudio. Se trata, en particular, de 
las siguientes situaciones: a. el desarrollo normativo interno de los derechos reconocidos en la $\mathrm{CADH}$; b. la configuración de las instituciones nacionales que inciden en el desarrollo o ejercicio de los derechos reconocidos en la Convención; c. la valoración de las circunstancias materiales que justifican la limitación de los derechos reconocidos en la Convención; d. la regulación de los derechos no reconocidos en la Convención; e. el alcance de la jurisdicción de la Corte IDH en los casos contenciosos, y f. el cumplimiento de las sentencias de la Corte IDH (NúÑEZ PoBlete, 2012, Sobre la doctrina del margen de apreciación nacional. La experiencia latinoamericana confrontada y el thelos constitucional de una técnica de adjudicación del derecho internacional de los derechos humanos 22-23).

\section{PUNTOS DE CONTACTO Y DIFERENCIAS EN LA RECEPCIÓN DE LA DOCTRINA DEL MARGEN DE APRECIACIÓN NACIONAL EN LOS SISTEMAS EUROPEO E INTERAMERICANO DE PROTECCIÓN DE LOS DERECHOS HUMANOS}

A la hora de realizar una comparación entre la recepción de la doctrina del margen de apreciación nacional por parte de ambos sistemas regionales de protección, lo primero que debe tenerse presente es que los contextos no son los mismos y, por consiguiente, que los pensamientos jurídicos no evolucionan del mismo modo dentro de ambientes políticos y sociales heterodoxos.

En este sentido, la aplicación de esta doctrina por parte de los organismos europeos presenta ciertas singularidades, debido al propio alcance del proceso de integración regional; mientras que el desarrollo en la jurisprudencia americana ha sido menos prolífico, debido a que los primeros casos sustanciados ante la 
Corte Interamericana planteaban fundamentalmente situaciones relacionadas con el derecho a la vida, la integridad personal, la prohibición de la tortura y el ejercicio de la libertad personal; unos derechos que orbitan en torno al núcleo duro del Derecho Internacional de los derechos humanos y que se encuentran más alejados del ámbito de aplicación de la noción del margen de apreciación nacional (PASCUAL ViVES, 2013 222).

Sin embargo, este último dato estadístico no resulta eficaz al momento de evaluar el grado de recepción de la doctrina en cada sistema, sino que lo que debe tenerse en cuenta son las ocasiones en las que la Corte Interamericana pudo haber recurrido a la utilización de esta doctrina y no lo hizo.

Entre las similitudes, podemos mencionar que, tanto el TEDH como la Corte IDH, se refieren al margen nacional de apreciación como el espacio limitado de interpretación que tiene el Estado frente a los derechos fundamentales, y recurren al principio de proporcionalidad como nexo entre el control judicial y el margen de apreciación nacional.

Sin entrar en un análisis exhaustivo de cada derecho, señalaremos que respecto de la jurisprudencia sobre la exclusión de las amnistías parece haber coincidencia entre la Corte IDH y el TEDH, en orden a no admitir la aplicación de leyes de amnistías autoconcedidas para obtener la impunidad de crímenes de lesa humanidad. Los principios desarrollados en los casos Almonacid ${ }^{17}$ o Barrios

17 Corte IDH. Caso Almonacid Arellano y otros Vs. Chile. Excepciones Preliminares, Fondo, Reparaciones y Costas. Sentencia de 26 de septiembre de 2006. Serie C No. 154. 
Altos $^{18}$ por la Corte IDH y en Ely Ould Dah vs. Francia ${ }^{19}$ por el TEDH, son notoriamente similares, en el sentido que las señaladas amnistías - como modos de restringir el derecho a la verdad, a la tutela judicial y a la reparación - quedan fuera de cualquier posibilidad de reconocimiento del margen de apreciación estatal (NúÑez Poblete 35-36).

Entre los casos donde no se advierte sintonía ocupa un lugar especial la jurisprudencia relativa a las restricciones a la libertad de expresión. En efecto, si se comparan los criterios seguidos por la Corte IDH en el fallo de la Última Tentación de Cristo ${ }^{20}$ con la argumentación del TEDH en los casos Wingrove ${ }^{21} \mathrm{u}$ Otto-Premingert $^{22}$ (en los cuales hay expresa referencia a la doctrina del margen de apreciación), es posible advertir cierta reticencia por parte de la Corte IDH para admitir que, bajo ciertas circunstancias, las autoridades nacionales están mejor capacitadas para decidir cuándo una determinada obra del intelecto ofende los sentimientos religiosos predominantes en una comunidad (NúÑEZ Poblete 36-37).

18 Corte IDH. Caso Barrios Altos Vs. Perú. Fondo. Sentencia de 14 de marzo de 2001. Serie C No. 75.

19 TEDH, caso Ould Dah vs. Francia (caso núm. 13.113/03), decisión de admisibilidad del 17 de marzo de 2009.

20 Corte IDH. Caso "La Última Tentación de Cristo" (Olmedo Bustos y otros) Vs. Chile. Fondo, Reparaciones y Costas. Sentencia de 5 de febrero de 2001. Serie C No. 73.

21 TEDH, Wingrove vs. Reino Unido (caso núm. 17.419/90), sentencia del 25 de noviembre de 1996.

22 TEDH, Otto-Preminger Institut vs. Austria (caso núm. 13.470/87), sentencia del 20 de septiembre de 1994. 


\section{LA DOCTRINA DEL MARGEN DE APRECIACIÓN NACIONAL EN LA JURISPRUDENCIA ARGENTINA}

En los acápites anteriores nos referimos a que la doctrina del margen de apreciación nacional tuvo sus orígenes y fue aplicada por los organismos internacionales de protección (del sistema europeo, en mayor medida)

En Argentina, el Estado nunca invocó esta teoría ante los organismos interamericanos que han tomado intervención en casos que lo tenían como sujeto demandado, sino que se limitó a utilizar la fórmula de la cuarta instancia, persiguiendo la inadmisibilidad del asunto sin entrar en el análisis de fondo y sin llegar a evaluar si correspondía recurrir al margen de apreciación nacional.

Por otra parte, en lo que hace a los antecedentes jurisprudenciales de casos resueltos a nivel interno, es posible observar que usualmente la doctrina es mencionada para uno de estos dos fines: negar que, en el tipo de supuesto de que se trate, exista margen alguno de apreciación para los Estados (por ejemplo, por el tipo de derechos que están en juego), o señalar que, dadas las características concretas del caso, cualquiera que sea el margen de apreciación que se conceda, la medida enjuiciada es inválida (ELIAS y RiVERA, 2012, "La doctrina del margen de apreciación nacional en el caso argentino" 127-128).

Así ha sucedido, en el caso Alianza Frente para la Unidad -de septiembre de 2001- cuando el Dr. Petracchi utilizó el concepto del margen de apreciación en sentido negativo, ya que la causa implicaba el análisis de la legitimidad de criterios discriminatorios. Al respecto, la CSJN entendió que la condición de inocentes de 
las personas detenidas pero no condenadas en un proceso penal, determina que no se pueda afectar su derecho a ser elegido en los $\operatorname{comicios}^{23}$, sin que exista sobre ello margen de apreciación nacional posible, dado que se encontraba involucrado un criterio de discriminación expresamente prohibido por la Convención Americana de Derechos Humanos, regla que el Estado debe respetar en pos de un adecuado control de convencionalidad. Así lo ha expresado el magistrado:

[...] [R]esulta inaceptable la afirmación del tribunal correntino, en el sentido de que la norma electoral provincial establecería una distinción que no importaría una discriminación arbitraria entre quienes se encuentran procesados detenidos y quienes gozan de libertad. En efecto, cuando un criterio discriminatorio está expresamente vedado -como resulta del art. 23 in fine del pactono existe margen de apreciación alguna para el legislador de rango inferior, el que debe limitarse a respetar la prohibición constitucional.

El Pacto de San José [...] sólo autoriza a "reglamentar" el ejercicio de los derechos políticos respecto de los condenados, categoría a la que no puede asimilarse la de los procesados, sea que estén o no detenidos [...] (CSJN, 2001, “Alianza

23 En este caso se solicitaba a la Justicia Electoral de la Provincia de Corrientes la habilitación de la candidatura a gobernador de Raúl Romero Feris, quien en ese momento se encontraba privado de la libertad sin condena. Para ello, se solicitó que se declarase la inconstitucionalidad e inaplicabilidad del art. $3^{\circ}$, inc. d, del Código Electoral Provincial y de los arts. 53 y 57 de la Constitución de la provincia. 
'Frente para la Unidad' (elecciones provinciales gobernador y vicegobernador, diputados $\mathrm{y}$ senadores provinciales) s/ oficialización listas de candidatos", considerando 10 del voto del Dr. Enrique Santiago Petracchi) ${ }^{24}$

Por otro lado, es importante traer a colación un momento histórico en el que el Estado argentino se encontró en una encrucijada entre lo establecido por el ordenamiento local y lo normado por un Tratado del cual es parte. Ante aquella situación, la doctrina del margen de apreciación fue utilizada -en disidencia- para respaldar una solución jurídica que diera preeminencia a una interpretación de normas constitucionales en aparente colisión con instrumentos internacionales.

Esto sucedió cuando el país decidió ser parte y otorgar jerarquía constitucional a la Convención sobre la Imprescriptibilidad de los Crímenes de Guerra y de los Crímenes de Lesa Humanidad. El conflicto normativo presentado en el caso Arancibia Clavel se

24 En el mismo sentido, en el caso Reyes Aguilera, donde se cuestionaba la validez de un requisito de residencia de 20 años en el país para los extranjeros que quisieran acceder a una prestación de la seguridad social por invalidez total, los jueces Fayt y Zaffaroni sostuvieron que: "[...] [P]or mayor que fuese el margen de apreciación que corresponda dispensar al legislador o reglamentador en la presente materia, no cabe duda alguna que sumar a dichos críticos requerimientos un lapso de residencia, en el caso, de 20 años - aun cuando también rigiera en igual medida para los argentinos, incluso nativos -, implica, puesto que la subsistencia no puede esperar, un liso y llano desconocimiento del derecho a la seguridad social, en los términos de los citados textos internacionales de jerarquía constitucional, en grado tal que compromete el derecho a la vida [...]" (CSJN, Reyes Aguilera, Daniela c/Estado Nacional, sentencia del 4 de septiembre de 2007, considerando 7) 
suscitó entre la aplicación retroactiva prevista por el instrumento y el principio de legalidad -receptado en el art. 18 de la Constitución Nacional- que impide imponer una pena en base a una ley que no fuera previa al hecho. Como cuestión anterior al análisis del caso, vale recordar que nuestra Carta Magna -en el artículo 27- dispone que los tratados deban ajustarse y guardar conformidad con los principios de derecho público establecidos en la Constitución.

Ante estos hechos, la mayoría de la Corte consideró constatada la existencia de una costumbre internacional respecto de la imprescriptibilidad de los crímenes de lesa humanidad, razón por la cual no se estaría aplicando retroactivamente el Tratado.

No obstante ello, es muy valioso el argumento esgrimido por el Dr. Fayt en su voto en disidencia. Entre los aspectos constitucionales e internacionales mencionados, se refiere al "margen nacional de apreciación", atreviéndose a esbozar no sólo una definición de la doctrina sino también su aplicación al caso concreto. En base a este análisis, el magistrado concluye que el artículo 27 previamente mentado no entra en colisión con esta teoría internacional y su aplicación permitiría la armonización entre el texto constitucional y la Convención. Sirvan los siguientes párrafos de ilustración:

[...] [E]n absoluta concordancia con el art. 27 de la Constitución Nacional también desde la ciencia del derecho internacional se reconoce actualmente lo que se denomina un "margen nacional de apreciación", doctrina nacida en la Comisión Europea de Derechos Humanos, adoptada por la Corte Europea de Derechos Humanos y recogida 
también por la Corte Interamericana de Derechos Humanos (conf. OC-4/84 del 19 de enero de 1984). Su esencia es garantizar, ciertamente, la existencia de la autonomía estatal, por la cual cada Estado tiene reservado un margen de decisión en la introducción al ámbito interno de las normas que provienen del ámbito internacional [...]

[...] Es claro que dentro de los principios que sin lugar a dudas integran ese "margen de apreciación" autónomo de cada Estado (en el que la soberanía estatal no cede frente a normas que se insertan desde el plano internacional) se encuentran los derechos fundamentales garantizados a los individuos por las constituciones estatales.

De esta manera la introducción de principios de derecho internacional encuentra su límite en la afectación de esos derechos fundamentales.

Es decir, se trata de adaptar las exigencias del derecho internacional (con el espacio de autonomías que se reservan los estados individuales) sin restringir las garantías básicas de las personas que, en el caso del derecho penal, no son otras que las que se encuentran sometidas a enjuiciamiento. Es indudable entonces, que sobre la base del art. 27, el constituyente ha consagrado ya desde antiguo un propio "margen nacional de apreciación" delimitado por los principios de derecho público establecidos en la Constitución Nacional, conformado por sus "artículos 14, 16, 17, 18 y 20 (...) franquicias (...) concedidas a todos los habitantes, como principios de derecho público, 
fundamentales del derecho orgánico interno y del derecho internacional argentino [...]

[...] [L]a vigencia del art. 27 impide claramente la aplicación de un tratado internacional que prevea la posibilidad de aplicación retroactiva de la ley penal, en tanto el principio de legalidad que consagra el nullum crimen nulla poena sine lege praevia es innegablemente un principio de derecho público establecido en esta Constitución (art. 18 De la Constitución Nacional), quizá uno de sus más valiosos. Es este margen nacional de apreciación el que determina que la garantía mencionada, consagrada a quienes son juzgados por tribunales argentinos, deba ser respetada estrictamente incluso tratándose de los denominados crímenes de lesa humanidad, cuando éstos se juzguen en el país [...] (CSJN, 2004, “Arancibia Clavel, Enrique Lautaro s/ homicidio calificado y asociación ilícita y otros -causa n 259-.", considerandos 18 y 19 de la disidencia del Juez Fayt)

La cuestión de la prescripción de las acciones penales no acabó con aquel fallo. En 2004 la Corte Suprema de Justicia de la Nación debió entender en el caso Espósito, luego de que éste fuera llevado ante la Comisión y la Corte Interamericana de Derechos Humanos ${ }^{25}$.

25 En aquella instancia el caso fue nominado Bulacio Vs. Argentina (Véase Corte IDH. Caso Bulacio Vs. Argentina. Fondo, Reparaciones y Costas. Sentencia de 18 de septiembre de 2003. Serie C No. 100) 
En la instancia local, en junio del 2001, fue declarada la prescripción de la acción penal por el juez de primera instancia y confirmada por la Cámara de Apelaciones en noviembre de 2002. Paralelamente, el caso había arrancado su rumbo en el Sistema Interamericano en 1997 y en Septiembre de 2003 la Corte Interamericana concluyó que el Estado Argentino era responsable internacionalmente $\mathrm{y}$, aplicando la doctrina sentada en el caso "Barrios Altos", determinó que debía proseguir la investigación y sancionar a los responsables, ya que una disposición de prescripción no podía obstar a esta obligación.

Es así como, cuando el caso llega a la Corte Suprema, ésta debía resolver, por un lado, si la acción penal en contra de Espósito estaba prescripta y, si así fuera, si debía considerar inaplicable la disposición de prescripción en razón de la sentencia de la Corte Interamericana. La resolución del Alto Tribunal fue que el juicio penal contra el comisario Espósito debía continuar, ya que la acción penal no estaba prescripta.

En lo que respecta al tema que nos ocupa, el argumento fue empuñado por el Dr. Boggiano, al entender que, si bien es cierto que las sentencias de la Corte Interamericana son vinculantes para el Estado argentino, por haber reconocido su competencia contenciosa, no es menos cierto que el Estado goza de un "margen de apreciación razonable" para definir cómo dar cumplimiento a lo ordenado por el Tribunal internacional. En sus propias palabras:

[...] [L]a solución a la que se arriba en cuanto a la imposibilidad de declarar la prescripción de la acción penal en esta causa, como parte del deber reparatorio que incumbe al Estado argentino, 
resulta de conformidad con la ley interna, en atención a las circunstancias particulares de la causa, y a las normas de la Convención según la inteligencia que le ha otorgado esta Corte por referencia a la jurisprudencia de la Corte Interamericana de Derechos Humanos (punto resolutivo 4 caso "Bulacio vs. Argentina"). En este sentido, existe un margen de apreciación razonable de los estados parte respecto al modo de hacer efectivo el deber de investigación y sanción de los responsables de las violaciones de los derechos humanos. Por ello no sería posible adoptar disposiciones de imprescriptibilidad para crímenes no alcanzados por las reglas de derecho internacional referidos por nuestro ordenamiento jurídico (Convención sobre Imprescriptibilidad de los Crímenes de Guerra y Lesa Humanidad). El principio de imprescriptibilidad derivado, tanto del derecho internacional consuetudinario, cuanto de la Convención de Imprescriptibilidad de Crímenes de Guerra y Lesa Humanidad, ha sido reconocido por esta Corte para los delitos de lesa humanidad [...] (CSJN, 2004, "Espósito, Miguel A.”, considerando 15 del voto del juez Boggiano)

Ahora bien, existe un único caso en el que la doctrina del margen de apreciación nacional se utilizó para rechazar una pretensión jurídica con base en disposiciones de tratados que gozan de jerarquía constitucional. Esto sucedió en 1999, cuando la Corte Suprema de Justicia de la Nación fue llamada a expedirse respecto de un caso que analizaba la falta de legitimación activa de una 
madre para deducir por derecho propio la acción de impugnación de paternidad matrimonial, conforme el art. 259 del Código Civil.

En aquella ocasión, el Tribunal entendió que los regímenes que regulan las instituciones de la maternidad y la paternidad son disímiles y se rigen por presunciones legales diferentes. Por esta razón, no merecen igual tratamiento legal y suponen una habilitación en cabeza de las autoridades estatales para establecer legítimas distinciones en base al orden jurídico y social establecido. En palabras de la Corte:

[...] [E]l Estado goza de un razonable margen de apreciación de las distinciones que, dentro de los parámetros mencionados, puede legítimamente formular por imperativos de bien común. En este orden de ideas, la paternidad y la maternidad no son absolutamente iguales y por ello, el legislador puede contemplar razonables diferencias. El art. 259 del Código Civil, que atribuye al marido y no a la mujer la acción de impugnación de la paternidad, no se funda en un privilegio masculino sino que suministra al marido la vía legal para destruir una presunción legal -que no pesa, obviamente, sobre la mujer, puesto que su maternidad queda establecida por la prueba del nacimiento y la identidad del nacido (art. 242 del Código Civil)- a fin de que el sujeto sobre quien opera la presunción tenga la posibilidad de desvirtuar que sea el padre del hijo de su esposa nacido dentro de los términos que fija la ley, desligándose así de las obligaciones de una 
paternidad que le es ajena [...] (CSJN, 1999, D. de P., V. c. O., C. H. s. impugnación de paternidad, considerando 14)

Para así entender, la CSJN se apoyó en la doctrina sentada por la Corte Europea de Derechos Humanos en el caso Kroon and others v. The Neherlands ${ }^{26}$, tomando como variable a considerar para el momento de la actividad legisferante los valores vigentes en la sociedad y el apropiado equilibrio procesal de las partes -en este caso, madre y padre.

[...] [L]a doctrina del caso "Kroon and others v. The Netherlands", fallado el 27 de octubre de 1994 por la Corte Europea de Derechos Humanos, que cita el señor Procurador General en su dictamen -fs. 341-, corrobora la idea de que las autoridades de los Estados tienen un razonable margen de apreciación para adoptar la política legislativa que estimen apropiada para asegurar el respeto a la vida familiar y permitir la formación de vínculos familiares perfectos, dentro de un estándar medio de protección. En el citado caso, la Corte de Estrasburgo apoyó el criterio de la Comisión, en el sentido de que constituía una falta de respeto a la vida privada y familiar -y un incumplimiento por parte del Estado a sus obligaciones internacionales- la circunstancia de que el derecho holandés impidiese la impugnación de paternidad a toda persona distinta del marido de la madre.

26 TEDH, Kroon and others v. The Neherlands, sentencia del 27 de octubre de 1994. 
Esta limitación permite distinguir el caso citado a fs. 341 , de la controversia sub examine, en que se halla en juego el art. 259 del Código Civil, que, como se ha dicho, atribuye legitimación activa, no sólo al marido sino, además, al hijo, y en todo tiempo [...]

[...] [U]na distinta composición de los valores en tensión podrá ser eventualmente consagrada por el Poder Legislativo de la Nación en ejercicio de su competencia propia, como lo han hecho, por ejemplo, ordenamientos legales vigentes en otros países, que no extienden a la madre la acción de impugnación de la paternidad -lo que resultaría absurdo a la luz de lo expresado en el precedente considerando 14 - sino que le confieren una acción diferente, configurados determinados requisitos (art. 318 del código francés vigente). De lege lata, cabe concluir que el art. 259 del Código Civil satisface el juicio de compatibilidad constitucional puesto que no transgrede los derechos fundamentales invocados por la recurrente, sino que plasma una reglamentación posible de los valores en tensión, en concordancia con los derechos y garantías de jerarquía constitucional [...] (CSJN, 1999, D. de P., V. c. O., C. H. s. impugnación de paternidad, considerando 16 y 17). 


\section{CONCLUSIONES}

La doctrina del margen de apreciación nacional se presenta cuando no es posible verificar la existencia de consenso internacional respecto a la cuestión a resolver y, al mismo tiempo, cuando las circunstancias del caso ameritan una deferencia hacia las autoridades estatales para que interpreten el sentido dado a la norma internacional.

En aquellos casos, los tribunales regionales han entendido que las particularidades propias del país donde fue invocado el derecho juegan un papel trascendental al momento de interpretar el alcance del mismo. En este sentido, se tiene en cuenta el contexto social, económico y jurídico nacional, valorando el lugar de subsidiaridad que debe guardar el derecho internacional de los derechos humanos frente a la soberanía estatal.

Sin embargo, no debe perderse de vista que este margen de apreciación no es absoluto, y se verá condicionado tanto por las obligaciones asumidas por el Estado en virtud del tratado del que es parte, como por la vigilancia que ejercen los organismos de control a partir de un estricto test de proporcionalidad.

Si bien el origen de la doctrina se remonta a la jurisprudencia del sistema europeo de protección de derechos humanos, su alcance ha trascendido las barreras regionales y ha encontrado una lábil aplicación por parte de los órganos del sistema.

Conforme lo analizado, en el caso del sistema interamericano, se trata por el momento de una figura muy débil, incluso residual debido a que, hasta la fecha, los casos que llegaban a la Corte eran de tal gravedad (lo que se conoce como gross violations 
como las violaciones del derecho a la vida, integridad personal, etc.) que el self restraint no tenía ninguna cabida.Aun así se trata de una figura jurisprudencial en auge que está, cada vez más, en sintonía con el mundo académico latinoamericano (SÁNCHEZMolinA, 2015-2016, "Margen de apreciación nacional (en los sistemas de protección internacional de los derechos humanos)" 229).

Sobre este punto, es interesante tomar la idea de la profesora chilena María Angélica BENAVIDES, quien propone la existencia de cierta tendencia de la Corte IDH hacia el universalismo, el reducido desarrollo democrático de la región y la juventud relativa del sistema interamericano (BENAVIDES, 2009, "El consenso y el margen de apreciación en la protección de los derechos humanos" 308 y 309)

En el mismo sentido, se observa el conflicto que existe entre la tendencia universalista de los derechos humanos como posiciones morales con pretensiones universales y el relativismo moral que de una manera u otra define a una determinada comunidad política. Ante la posible inexistencia de una solución absoluta, el Margen de apreciación nacional viene a ser ese espacio o válvula de escape en la cual se le da un determinado peso a la posición estatal, en cuanto a la apreciación del interés nacional preponderante que influye en la interpretación, delimitación, restricción y protección de un derecho convencional (REYES-TORRES, 2015, "Una cuestión de apreciación: el margen de apreciación en la Corte Interamericana de los Derechos Humanos" 2).

Tal es así que en el repaso de las decisiones del TEDH y la Corte Interamericana es posible concluir que la defensa del principio de subsidiariedad y el reconocimiento de diversos órdenes y sistemas 
jurídicos constituyen los principales objetivos perseguidos al invocar el concepto del margen de apreciación nacional.

En el caso argentino, en particular, se observa una recepción cautelosa de esta doctrina. La Corte Suprema de Justicia de la Nación ha recurrido a antecedentes del Tribunal Europeo para hacer lugar al espacio discrecional que corresponde al Estado frente a sus obligaciones internacionales. Sin embargo, consideramos que el alto Tribunal debiera adoptar una postura más progresista, acorde a los estándares establecidos por la jurisprudencia europea.

Los detractores de esta doctrina temen que a través de ella se conculque la esencia misma de la protección internacional. Al respecto opina SAGÜEZ que si bien es importante reconocer que ciertos derechos encuentran condicionamientos materiales y sociales derivados del ambiente donde se aplican, hay un margen nacional "aceptable" (flexible), que admitiría ciertas modalidades secundarias de aplicación y extensión, atendiendo las idiosincrasias y experiencias de cada país, y hay otro margen "inadmisible", integrado por un núcleo duro de derechos de fuente internacional, esenciales, básicos y por lo tanto inalterables e innegociables. Sobre estos últimos no cabrían restricciones de interpretación a cargo de las soberanías estatales. Para el citado autor, ambas doctrinas deben coexistir lo más armónicamente posible (Trucco, El control de convencionalidad en la interpretación de la Corte Interamericana de Derechos Humanos y su recepción por los tribunales nacionales19-22)

Debe tenerse presente que el margen de apreciación nacional no da lugar a una reserva de inmunidad a favor de los Estados, sino que refleja el principio de subsidiaridad y permite que el Estado 
actúe para responder a su realidad. El margen de apreciación es, de esta forma, la deferencia a favor del Estado respecto a tensiones generadas por realidades jurídicas-sociales (REYESToRRES, 1-2)

Asuntos como el de la protección de los derechos de las minorías étnicas y culturales, la discusión sobre el aborto frente al derecho a la vida, la libertad de expresión frente a sus límites intrínsecos o el caso del matrimonio homosexual son temas en los cuales los tribunales regionales, especialmente el Europeo, han aplicado esa noción (BArbosa Delgado, 60).

Por último, referiremos que es nuestra opinión que la actual renovación de los magistrados de la Corte Suprema de la Nación brinda un escenario propicio para la apertura hacia la doctrina del margen de apreciación, conforme los alcances definidos por el Tribunal Europeo. 


\section{BIBLIOGRAFÍA}

BARBOSA Delgado, Francisco R. El margen nacional de apreciación en el derecho internacional de los derechos humanos: entre el estado de derecho y la sociedad democrática. México: Universidad Nacional Autónoma de México. Instituto de Investigaciones jurídicas, 2012: 51-82, <http://bibliohistorico.juridicas.unam.mx/ libros/7/3160/7.pdf $\geq$ [Consulta al 29/07/2016]

, "Los límites a la doctrina del margen nacional de apreciación en el Tribunal Europeo y la Corte Interamericana de Derechos Humanos: intervención judicial en torno a ciertos derechos de las minorías étnicas y culturales.", Revista Derecho del Estado. Nueva serie 26 (2011), < http://revistas.uexternado.edu.co/index.php/ derest/article/view/2881/3041> [Consulta al 29/07/2016]

BENAVIDES, María Angélica. "El consenso y el margen de apreciación en la protección de los derechos humanos". Ius et Praxis 15/1 (2009)

CANÇADO TRINDADE, Antonio, El derecho internacional de los derechos humanos en el siglo XXI, 2a. ed., Santiago: Editorial Jurídica de Chile, 2006.

DÍAZ CREGO, María. "Margen de apreciación". Diccionario Iberoamericano de Derechos Humanos y fundamentales. España: Universidad de Alcalá. AECID, 2011, <http:// diccionario.pradpi.org/inicio/index.php/terminos_pub/ view/94 $\geq$ [Consulta al 29/07/2016] 
ELÍAS, José Sebastián y RIVERA, Julio César (h), La doctrina del margen de apreciación nacional en el caso argentino. México: Universidad Nacional Autónoma de México. Instituto de Investigaciones jurídicas, 2012: 85-135,<http:// bibliohistorico.juridicas.unam.mx/libros/7/3160/8.pdf $\geq$ [Consulta al 29/07/2016]

FAÚNDEZ LEDESMA, Héctor, El sistema interamericano de protección de los derechos humanos. Aspectos institucionales y procesales, 3a. ed., San José: Instituto Interamericano de Derechos Humanos, 2004.

GARCÍA ROCA, Javier. "La muy discrecional doctrina del margen de apreciación nacional según el tribunal europeo de derechos humanos: soberanía e integración." Teoría y Realidad Constitucional 20, 2007: 117-143.

GONZÁlEZ VEGA, Javier A. "Interpretación, Derecho Internacional y Convenio Europeo de Derechos Humanos: a propósito de la interpretación evolutiva en materia de autodeterminación sexual". Revista Española de Derecho LVI -1, Enero 2004

LEGG, A., The Margin of Appreciation in International Human Rights Law. Deference and Proportionality, Oxford: Oxford University Press, 2012

NÚÑEZ POBLETE, Manuel, Sobre la doctrina del margen de apreciación nacional. La experiencia latinoamericana confrontada y el thelos constitucional de una técnica de adjudicación del derecho internacional de los derechos humanos. México: Universidad Nacional Autónoma de México. Instituto de Investigaciones jurídicas, 2012: 3-49, <http://bibliohistorico.juridicas.unam.mx/ libros/7/3160/6.pdf> [Consulta al 29/07/2016] 
Pascual VIVES, Francisco José. "El margen de apreciación nacional en los tribunales regionales de derechos humanos: una aproximación consensualista". Anuario Español de Derecho Internacional 29, 2013: 217-262

REYES TORRES, Amaury A. Una cuestión de apreciación: el margen de apreciación en la Corte Interamericana de los Derechos Humanos, Working Paper 1/2015-AART, $<$ https://www.academia.edu/10416869/Una_cuesti $\%$ C3\%B3n_de_apreciaci\%C3\%B3n_El_margen_de_ apreciaci \%C3\%B3n_en_la_Corte_Interamericana_de_ los_Derechos_Humanos> [Fecha de Consulta: 29/07/ 2016]

SAGÜEZ, Néstor P. "La interpretación de los Derechos Humanos en las jurisdicciones nacional e internacional". Anticipo de "Anales" Año XLII - Segunda época - Número 36, Buenos Aires: Academia Nacional de Derechos y Ciencias Sociales de Buenos Aires, 1998.

"Las relaciones entre los Tribunales Internacionales y los Tribunales Nacionales en materia de derechos humanos. Experiencias en Latinoamérica". Revista Ius et Praxis Vol 9 núm. 001, 2003.

SÁNCHEZ-MOLINA, Pablo. "Margen de apreciación nacional (en los sistemas de protección internacional de los derechos humanos)". Eunomía. Revista en Cultura de la Legalidad 9, octubre 2015 - marzo 2016: 224-231.

TRUCCO, Marcelo F. El control de convencionalidad en la interpretación de la Corte Interamericana de Derechos Humanos y su recepción por los tribunales nacionales, <https://www.uai.edu.ar/investigacion/ contenidos/ganadores/ganadores-2013_E1\%20 control $\% 20 \mathrm{de} \% 20$ convencionalidad $\% 20$ en $\% 201 \mathrm{a} \% 20$ interpretaci\%C3\%B3n\%20de\%201a\%20Corte $\% 20$ 
Interamericana\%20de\%20Derechos\%20Humanos.pdf-> [Consulta al 29/07/2016]

CEDH, Dinamarca, Noruega, Suecia y Países Bajos c. Grecia, dictamen del 5 de noviembre de 1969.

CEDH, Grecia c. Reino Unido, dictamen del 26 de septiembre de 1958.

CEDH, Lawless c. Irlanda, dictamen del 19 de diciembre de 1959.

TEDH, Animal Defenders International v. United Kingdom, sentencia del 22 de abril de 2013

TEDH, Caso relativo a ciertos aspectos de la legislación lingüística de la enseñanza en Bélgica, sentencia del 23 de julio de 1968.

TEDH, De Wilde, OOms et Versyp contra Bélgica, del 10 de marzo de 1972.

TEDH, Eweida v. Reino Unido, sentencia del 15 de enero de 2013.

TEDH, Fedorenko contra Ucrania, de 1 de junio de 2006.

TEDH, Handyside v. United Kingdom, sentencia del 7 de diciembre de 1976.

TEDH, Irlanda $v s$. Reino Unido, sentencia del 25 de enero de 1976.

TEDH, Kroon and others v. The Neherlands, sentencia del 27 de octubre de 1994.

TEDH, Lingüístico Belga, sentencia del 24 de junio de 1965.

TEDH, Otto-Preminger Institut vs. Austria, sentencia del 20 de septiembre de 1994.

TEDH, Ould Dah vs. Francia, decisión de admisibilidad del 17 de marzo de 2009.

TEDH, Rasmussen v. Denmark, 28 November 1984.

TEDH, Wingrove $v s$. Reino Unido, sentencia del 25 de noviembre de 1996. 
CIDH, Informe núm. 25/01, caso núm. 12.144, Álvaro Robelo González vs. Nicaragua, 5 de marzo de 2001.

CIDH, Informe Núm. 25/04, petición núm. 12.361 Admisibilidad, Ana Victoria Sánchez Villalobos y otros vs. Costa Rica, 11 de marzo de 2004.

CIDH, Informe núm. 30/93, caso núm. 10.804, José Efraín Montt vs. Guatemala, 12 de octubre de 1993.

CIDH,Informe Núm. 50/05, petición núm. 369-04 Admisibilidad, Jorge Luis Cháves Cambronero vs. Costa Rica, 12 de octubre de 2005.

CIDH, Informe Núm. 71/99, caso núm. 11.656, Marta Lucía Álvarez Giraldo vs. Colombia, 4 de mayo de 1999.

Corte IDH, Propuesta de Modificación a la Constitución Política de Costa Rica Relacionada con la Naturalización. Opinión Consultiva OC-4/84 del 19 de enero de 1984. Serie A No. 4.

Corte IDH. Caso "La Última Tentación de Cristo" (Olmedo Bustos y otros) Vs. Chile. Fondo, Reparaciones y Costas. Sentencia de 5 de febrero de 2001. Serie C No. 73.

Corte IDH. Caso Almonacid Arellano y otros Vs. Chile. Excepciones Preliminares, Fondo, Reparaciones y Costas. Sentencia de 26 de septiembre de 2006. Serie C No. 154.

Corte IDH. Caso Barreto Leiva Vs. Venezuela. Fondo, Reparaciones y Costas. Sentencia de 17 de noviembre de 2009. Serie C No. 206

Corte IDH. Caso Barrios Altos Vs. Perú. Fondo. Sentencia de 14 de marzo de 2001. Serie C No. 75.

Corte IDH. Caso Bulacio Vs. Argentina. Fondo, Reparaciones y Costas. Sentencia de 18 de septiembre de 2003. Serie C No. 100.

Corte IDH. Caso Castañeda Gutman Vs. México. Excepciones Preliminares, Fondo, Reparaciones y Costas. Sentencia de 6 de agosto de 2008. Serie C No. 184 
Corte IDH. Caso Chaparro Álvarez y Lapo Íñiguez Vs. Ecuador. Excepciones Preliminares, Fondo, Reparaciones y Costas. Sentencia de 21 de noviembre de 2007. Serie C No. 170 Corte IDH. Caso Herrera Ulloa Vs. Costa Rica. Excepciones Preliminares, Fondo, Reparaciones y Costas. Sentencia de 2 de julio de 2004. Serie C No. 107

Corte IDH. Caso Kimel Vs. Argentina. Fondo, Reparaciones y Costas. Sentencia de 2 de mayo de 2008. Serie C No. 177.

Corte IDH. Caso López Álvarez Vs. Honduras. Fondo, Reparaciones y Costas. Sentencia de 1 de febrero de 2006. Serie C No. 141.

Corte IDH. Caso Palamara Iribarne Vs. Chile. Fondo, Reparaciones y Costas. Sentencia de 22 de noviembre de 2005. Serie C No. 135.

Corte IDH. Caso Perozo y otros Vs. Venezuela. Excepciones Preliminares, Fondo, Reparaciones y Costas. Sentencia de 28 de enero de 2009. Serie C No. 195.

Corte IDH. Caso Ricardo Canese Vs. Paraguay. Fondo, Reparaciones y Costas. Sentencia de 31 de agosto de 2004. Serie C No. 111.

Corte IDH. La colegiación obligatoria de periodistas (Arts. 13 y 29 Convención Americana sobre Derechos Humanos). Opinión Consultiva OC-5/85 de 13 de noviembre de 1985. Serie A No. 5.

CSJN, "Arancibia Clavel, Enrique Lautaro s/ homicidio calificado y asociación ilícita y otros -causa n ${ }^{\circ} 259$-.", sentencia del 24 de agosto de 2004.

CSJN, "Alianza 'Frente para la Unidad' (elecciones provinciales gobernador y vicegobernador, diputados y senadores provinciales) s/ oficialización listas de candidatos", sentencia del 27 de septiembre de 2001. 
CSJN, "Espósito, Miguel A.”, sentencia del 23 de diciembre de 2004.

CSJN, "D. de P., V. c. O., C. H. s. impugnación de paternidad", sentencia del $1^{\circ}$ de noviembre de 1999.

CSJN, "Reyes Aguilera, Daniela c/Estado Nacional", sentencia del 4 de septiembre de 2007. 